\title{
Characteristics of Complex Systems in Sports Injury Rehabilitation: Examples and Implications for Practice
}

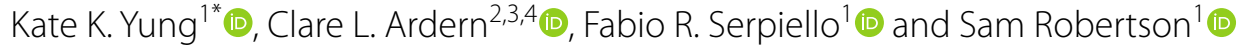

\begin{abstract}
Complex systems are open systems consisting of many components that can interact among themselves and the environment. New forms of behaviours and patterns often emerge as a result. There is a growing recognition that most sporting environments are complex adaptive systems. This acknowledgement extends to sports injury and is reflected in the individual responses of athletes to both injury and rehabilitation protocols. Consequently, practitioners involved in return to sport decision making (RTS) are encouraged to view return to sport decisions through the complex systems lens to improve decision-making in rehabilitation. It is important to clarify the characteristics of this theoretical framework and provide concrete examples to which practitioners can easily relate. This review builds on previous literature by providing an overview of the hallmark features of complex systems and their relevance to RTS research and daily practice. An example of how characteristics of complex systems are exhibited is provided through a case of anterior cruciate ligament injury rehabilitation. Alternative forms of scientific inquiry, such as the use of computational and simulation-based techniques, are also discussed - to move the complex systems approach from the theoretical to the practical level.
\end{abstract}

Keywords: Complexity, Return to sport, Return to play, Decision making, Machine learning, Bayesian network

\section{Key Points}

- Complex systems have distinct properties, such as nonlinearity, emergence and adaptation. Sixteen features of complex systems have been identified in sports injury rehabilitation.

- Rehabilitation practitioners may connect complex systems theory with their operations in the sports setting.
${ }^{*}$ Correspondence: kai.yung@live.vu.edu.au

${ }^{1}$ Institute for Health and Sport, Victoria University, Melbourne, Australia Full list of author information is available at the end of the article

\section{Challenges in Return to Sport Decision Making}

Return-to-sport (RTS) can challenge health professionals, coaches (i.e., practitioners) and athletes. In competitive sports, where marginal gains in performance are sought, athletes and practitioners often weigh risks and benefits when making the RTS decisions. In a team sports setting, full availability of players allows greater flexibility in tactical planning, such as deciding the best team formation based on the opponent's playing style. Player availability is linked to performance [1-3] and could reduce the financial burden on the team $[4,5]$.

Research on RTS decision making largely focuses on identifying a criteria list based on biological factors and on whether the athlete has returned to baseline performance level (e.g., Grindem et al. [6], Stares et al. [7], and Kyritsis et al. [8]). This approach has assisted practitioners in being transparent in the decision process, for instance, to grant a medical clearance. However, 


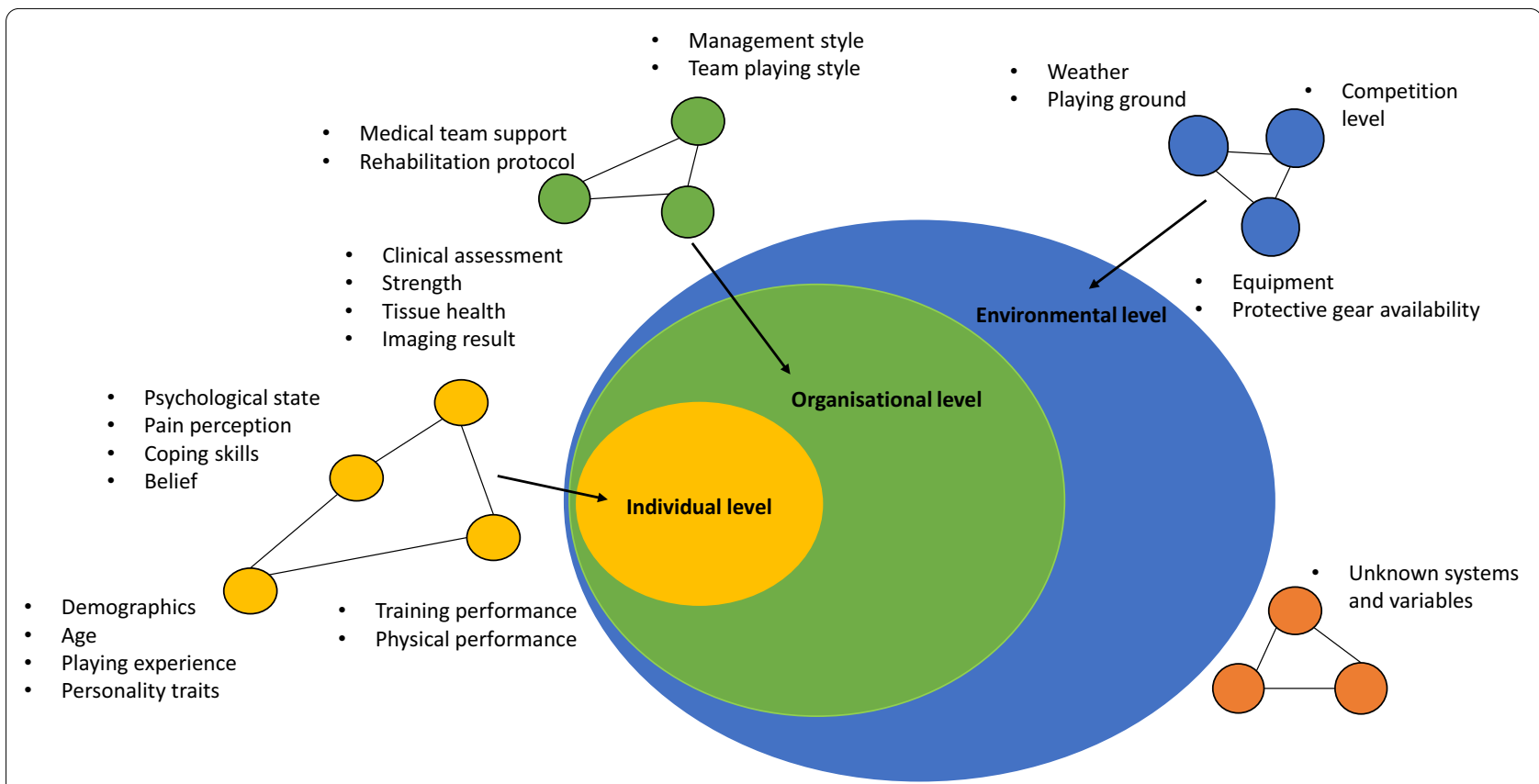

Fig. 1 A multilevel system map with factors related to return to sport decision in anterior cruciate ligament injury

underlying complexity and the high degree of interlinks, independencies, and temporal components also need consideration. For example, the same criteria may not apply to athletes of a different mental state, age group or playing level. Furthermore, non-linearity is commonly seen in the context of sports. As an example, most football fans would know that a team composed of the bestskilled players, does not necessarily produce the best performance. Instead, the outcome is highly dependent on the interplay of tactical, physiological, social and even emotional factors. Similarly, it may be beneficial to view RTS more than simply addressing a set of predefined RTS criteria, or achieving an arbitrary numerical change in a performance test.

To address these limitations and objectives, we propose an approach using the complex systems theory. Recent work from Bittencourt et al. [9] has raised awareness of the theory and more could be done to clarify the characteristics of complex systems and to increase the practical utility of the complex systems approach. Consequently, this paper builds on the work of Bittencourt et al. [9] and aims to (1) clarify the terminologies in the complex systems approach and adapt them for sports, (2) provide examples relevant to rehabilitation and (3) introduce tools that can model the complexity and increase practical utility in applied settings.

\section{What is a Complex Systems Approach?}

\section{A Complex Systems Approach to Decision Making in Sports Medicine}

The complex systems theory, with more than 50 years of history [10], acknowledges the multifaceted nature of sports and seeks to understand the interactions among different factors and the outcomes of the systems $[9,11]$. Complex systems are dynamic, open systems [12]. They are characterised by non-linearity due to feedback loops and interaction among the factors. This means that outputs are not always proportional to the inputs, and a small adjustment may lead to a large change in the systems and vice versa [13].

In complex systems, factors that interact with each other to form the systems are known as units [12]. In the context of RTS, these units could include age, wellness, biological healing of injured tissue, stress, external pressure and injury history. The units interact and define the space and dimension of the systems [14]. Consequently, different systems within systems emerge. These systems may be categorised based on their nature, for example, biomechanical, physiological and psychological. They may also be hierarchical and of multiple levels, namely individual, organisational and environmental (see Fig. 1). The individual level represents factors related to 
the individual athlete, from tissue healing to personal traits. The organisational level represents external factors related to the sporting club, organisation and support team, e.g., the coaching and medical team. The environmental level covers factors beyond the organisational level, such as the weather, playing schedule and competition level.

In recent years, the complex systems approach has gained momentum and has been used to understand sports injury occurrence $[9,15]$ and behaviour in sports performance [16-19]. However, the terminologies used in complex systems are often less familiar to practitioners and could be easily confused with merely complicated or multifactorial. Most studies recognize the importance of considering multiple factors in determining readiness for RTS or in the context of injury recognition $[6,8,9,20-$ 26], but more work is required to raise awareness on why the lens of complex systems approach should be adopted by practitioners in rehabilitation.

\section{Applying a Complex Systems Model for ACL rehabilitation} This paper provides examples based on the 16 common features of complex systems recently illustrated by Boehnert et al. [27]. They are adapted for the context of sports in Table 1, with examples illustrated mainly from an anterior cruciate ligament (ACL) injury.

An ACL injury is used here as the case illustration as it is a serious injury that may threaten the career of an athlete $[28,29]$. The estimated annual medical cost associated with ACL reconstruction surgery in Australia was over A $\$ 75$ million per year [30]. Currently, there is no consensus regarding the optimal functional rehabilitation criteria [20] and objective physiological RTS criteria [31]. Despite ACL injuries being one of the most researched topics in the sports medicine literature [32], the re-injury risk of ACL remains high [33, 34]. The complexity within ACL RTS may be explained at the individual, organisational and environmental levels.

\section{Implications for Practice and Future Research}

By illustrating the features of complex systems with a common sports injury, we highlight their practical utility in RTS. The complex systems approach provides a theoretical framework for interpreting the patterns that emerge from biopsychosocial and other external factors. In ACL rehabilitation, conducting independent clinical tests and functional assessments may provide useful information regarding the athletes' physical and mental status. However, a complex systems approach facilitates a more complete picture of the problem and an increased awareness of how different factors may interact.
There are two challenges on using the complex systems approach: (1) the high degree of complexity may deter practitioners who do not have formal training in handling large and complex datasets from using this approach, (2) Unlike studying in a controlled laboratory environment, it is near impossible to isolate a portion of the larger systems (i.e., isolation of the biological healing process from broader biopsychosocial factors). Fortunately, many computer-based decision support systems now have the capability of incorporating features of complex systems in their design and utility. For example, to operationalise one of the above features, "change over time", the working model can allow flexibility in updating the baseline and encourage repeated testing at multiple time points during the rehabilitation. We believe practitioners who develop an understanding of complex systems will be well-positioned to efficiently articulate their needs with analysts and ultimately develop decision support systems that inform best practices (e.g., RTS decision making).

Computer simulation (e.g., agent-based modelling), machine learning and Bayesian network $(\mathrm{BN})$ analyses are all potential tools for analysing both non-complex or complex systems [35]. These methods can consider the dynamic interaction at multiple levels simultaneously, consequently viewing RTS more completely and supporting decision making. These analytical tools may help to achieve the following: (1) allow practitioners to study and compare the potential outcome (e.g., likelihood of reinjury) of different decisions that are otherwise almost impossible to test safely in real life, (2) increase the decision efficiency by learning from previous experience and streamlining data from multiple sources and formats, (3) identify patterns in data that may cause a certain outcome.

These techniques can be used to construct clinical decision support systems, which may complement or be superior to human decisions. In a review of seventy studies, a decision support system improved clinical practice in $68 \%$ of trials [36]. These decision support systems have also provided more accurate diagnoses than human experts in some medical fields [37, 38]. Yet, the application of these approaches in RTS is still scarce in the literature. As such, we have provided a vignette here to outline how machine learning techniques and Bayesian networks could be applied to support RTS decision making: a 30-year-old professional female football player tore her hamstring 10 days ago during the season and a grade II hamstring strain was diagnosed. There is an important match in 2 weeks and there are six relevant questions, as covered in the below sections, which the practitioners and the coach would like to ask. Ultimately, the coach would like to know as early as possible about 


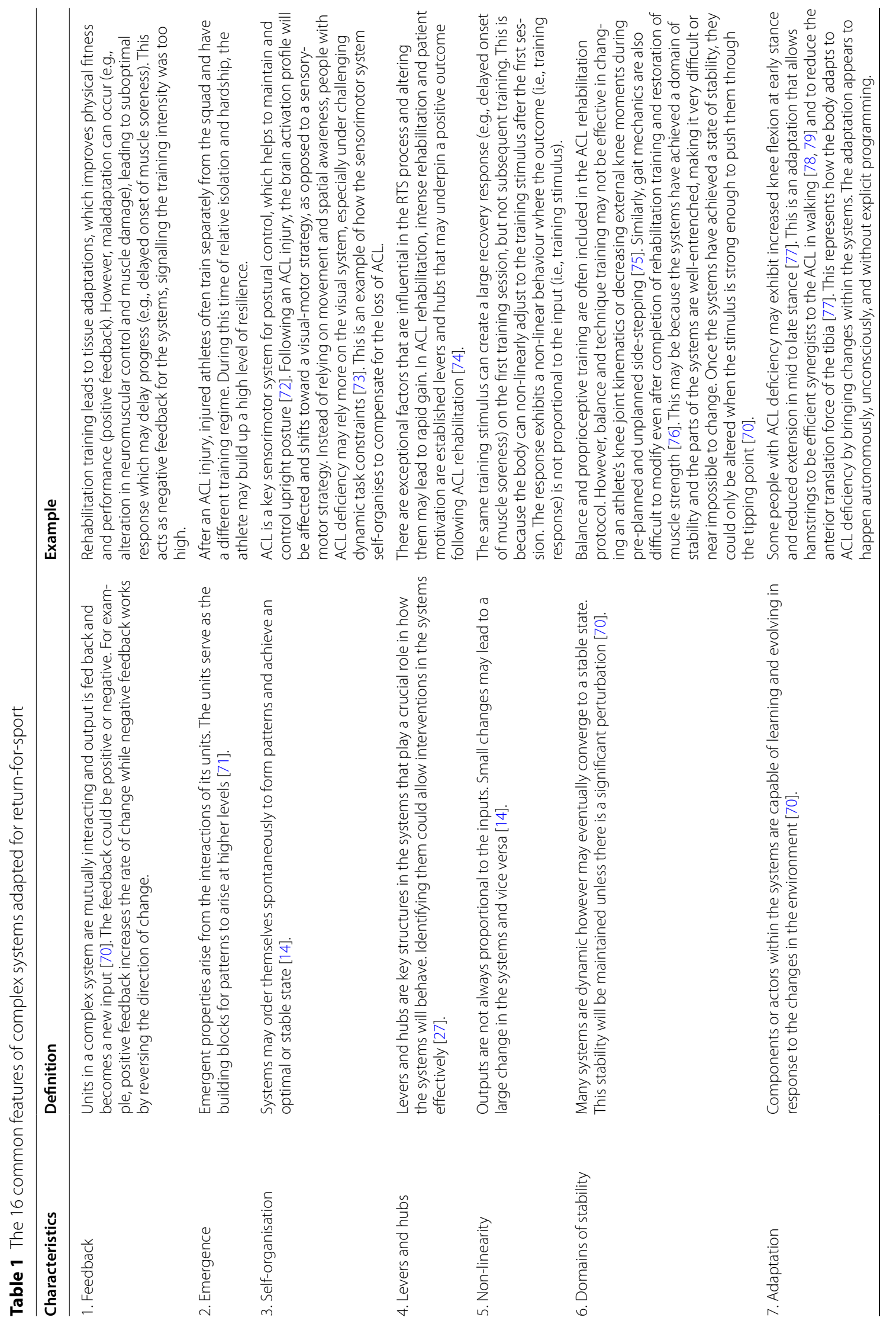




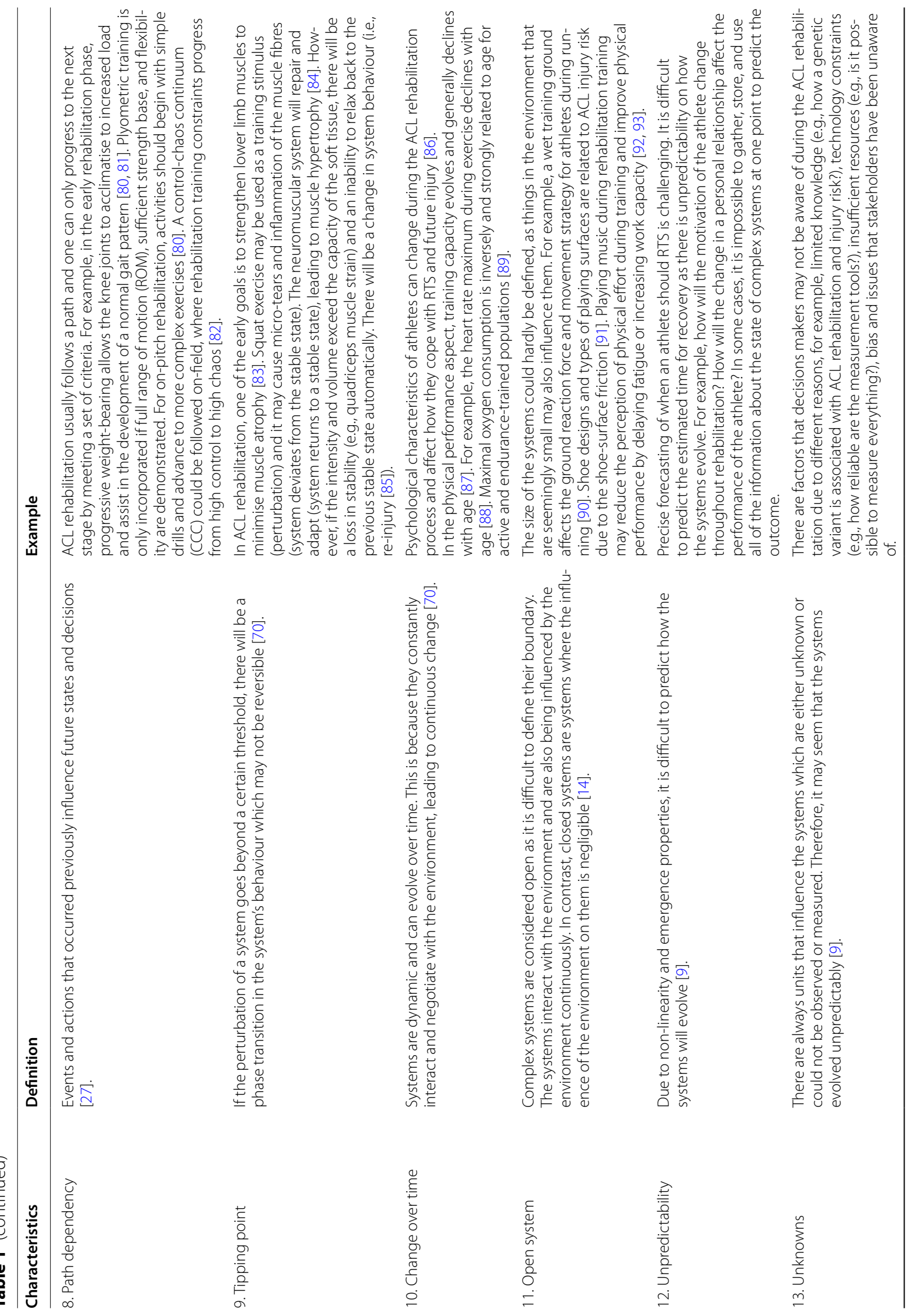




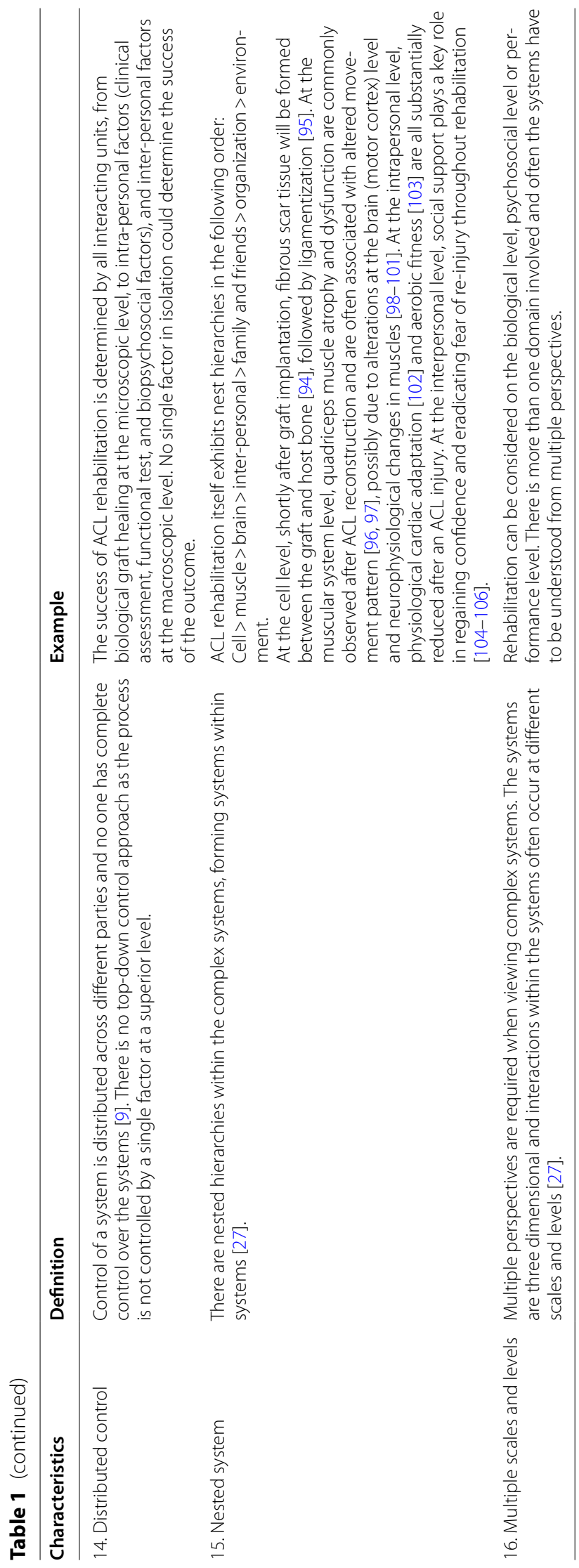


the availability of the player so that they could plan the players' list and hence the game strategy.

\section{Machine Learning Techniques}

As a subfield of artificial intelligence (AI), machine learning focuses on the use of data to train algorithms that can make classifications or predictions $[39,40]$. That is, it could recognise new meaningful correlations, patterns and trends in a large amount of data [41]. Not only are machine learning techniques suitable for non-complex analysis, but they can also accommodate multi-dimensional analysis in sport [42, 43]. New data could also be input into the model for it to learn and improve the task, leading to refinement of skills [40].

The goals of machine learning techniques in sports medicine setting can be divided into predictive and descriptive modelling [44]. Specifically, predictive modelling can be used for injury prognosis, diagnosis, and rehabilitation planning. Descriptive modelling can be used to characterize the general property of an injury, such as its severity, as well as include hypotheses of causality. However, as with traditional statistical approaches, machine learning techniques are simply a method for analysing the data, providing a prescriptive or descriptive output. For understanding and estimating causal relationships, appropriate study designs are required, for example, randomised controlled trials. Machine learning is often characterised by five major approaches (i.e., association, classification, clustering, relationship modelling and reinforcement learning), each having already been applied for injury risk assessment and/or performance prediction in sports [45-49]. Each of these approaches could serve as the methods to answer questions relevant to RTS.

\section{Question 1: Should the Athlete Progress to Full Training?}

Scenario The athlete has completed 10 days of rehabilitation training. The practitioners would like to assess whether the athlete is ready to progress to full training. An association approach could be used here, using the rule-based system (Table 2).

Rule-based approaches identify meaningful and frequent patterns between variables in a large dataset [50]. Often less identifiable by the practitioner, the rules may help them identify patterns that indicate optimal rehabilitation combinations of variables by flagging both commonly occurring and meaningful patterns in data.

In the above hypothetical example, a multivariate analysis of rules associated with a rehabilitation outcome is conducted. The model was set to only produce 3 categories of rules that contained the rehabilitation outcome as a result (i.e., ready for full training, not yet ready and unchanged). These could be the three rules most strongly associated with the rehabilitation outcome. A tick represents the presence of the context within the rule. The system could identify the number of rules required based on previous rehabilitation experience and to implement the rules when the complexity of the content is beyond human brain capacity. An increased number of rules may better represent complexity; however, it may potentially make the solution more difficult to operationalize practically.

\section{Question 2: What is the Likelihood that the Athlete Could Return to the Pre-injury Level Given the Current Level of Training?}

Scenario There are only 2 weeks until an important match. The coach would like to know the likelihood that the athlete could return to pre-injury level by then. Given the volume of high-speed running training that the athlete has completed, a classification method could be used to identify the likelihood (Table 3).

A decision tree uses dichotomous divisions to create the classification algorithm. Representing the rules, the decision tree could be used to develop a clinical decision algorithm for RTS $[49,51]$. Each node denotes a test on an attribute value and each branch represents an outcome of the test, with the leaves representing the class.

The above is a graphical representation of the decision tree that used a classification algorithm to identify the probability of RTS from a hamstring injury. Each node is associated with a rule condition, which branches off to the child node. In this example, the outcome of RTS is likely a non-linear relationship with the training volume and mental readiness, which is a characteristic of the complex systems approach (see Table 1, example 5). Using the classification approach may help to include non-linearity into analyses.

\section{Question 3: When is the Athlete Expected to Return to Sport?}

Scenario The coach would like to know when the athlete is expected to RTS based on the experience of the clinician and also accounting for the athlete's age. Clustering technique could be used to analyse the past data.

Clustering allocates data points into groups that share similar or dissimilar features [52]. In RTS, this may be useful in the allocation of multiple athletes to training groups. This could be done for clinical presentation, playing position, demographics, or inter-and intra-personal factors.

Table 4 visualizes one of the multiple approaches to which injured athletes could be clustered. Each dot represents an injured athlete and is coloured based on their severity. Size represents a measure of each athlete's age, with a larger size representing older age. They are further 
Table 2 The association approach to determine should the athlete progress to full training

\begin{tabular}{|l|l|l|l|l|}
\hline $\begin{array}{l}\text { Rule 1 } \\
\text { Range of motion full }\end{array}$ & $\begin{array}{l}\text { Rule 2 } \\
\text { Limb asymmetry index 100\% }\end{array}$ & $\begin{array}{l}\text { Rule 3 } \\
\text { Training load }>100 \% \text { match } \\
\text { requirement }\end{array}$ & Rule... & Decision \\
\hline$\checkmark$ & $\checkmark$ & $\checkmark$ & $\checkmark$ Ready for full training. \\
progress
\end{tabular}

Table 3 The classification approach to identify the likelihood for an athlete to RTS

\begin{tabular}{ll}
\hline Approach & Classification \\
Task & Supervised \\
Technique & Decision tree and random forest \\
Output type & Categorical or continuous \\
& Examples: ready to compete, not yet ready to compete
\end{tabular}

Application example

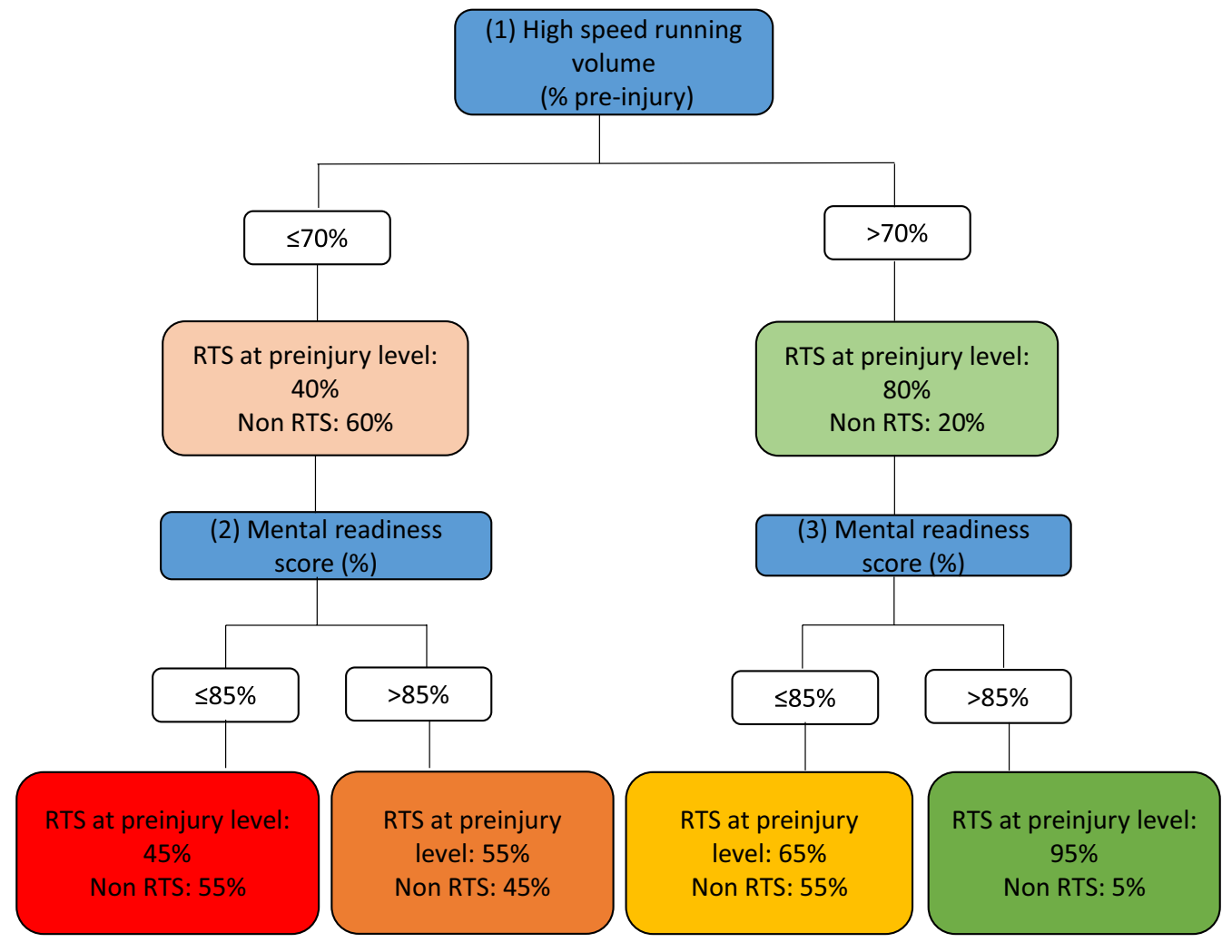

grouped into three different clusters, representing the severity and time to RTS. In this hypothetical example, the model output is the predicted days to RTS. However, it could also be designed to produce categorical outputs such as being ready to train or not yet ready to train.
Question 4: The Athlete has a High Level of Mental Readiness. Would that Change the Level of Confidence About the Athlete's Readiness to Play in an Important Game?

Scenario From the clustering approach, the coach has considered that the athlete may require at least 2 weeks to return to competition at pre-injury level. However, the 
Table 4 The clustering approach to identify when the athlete may return to sport

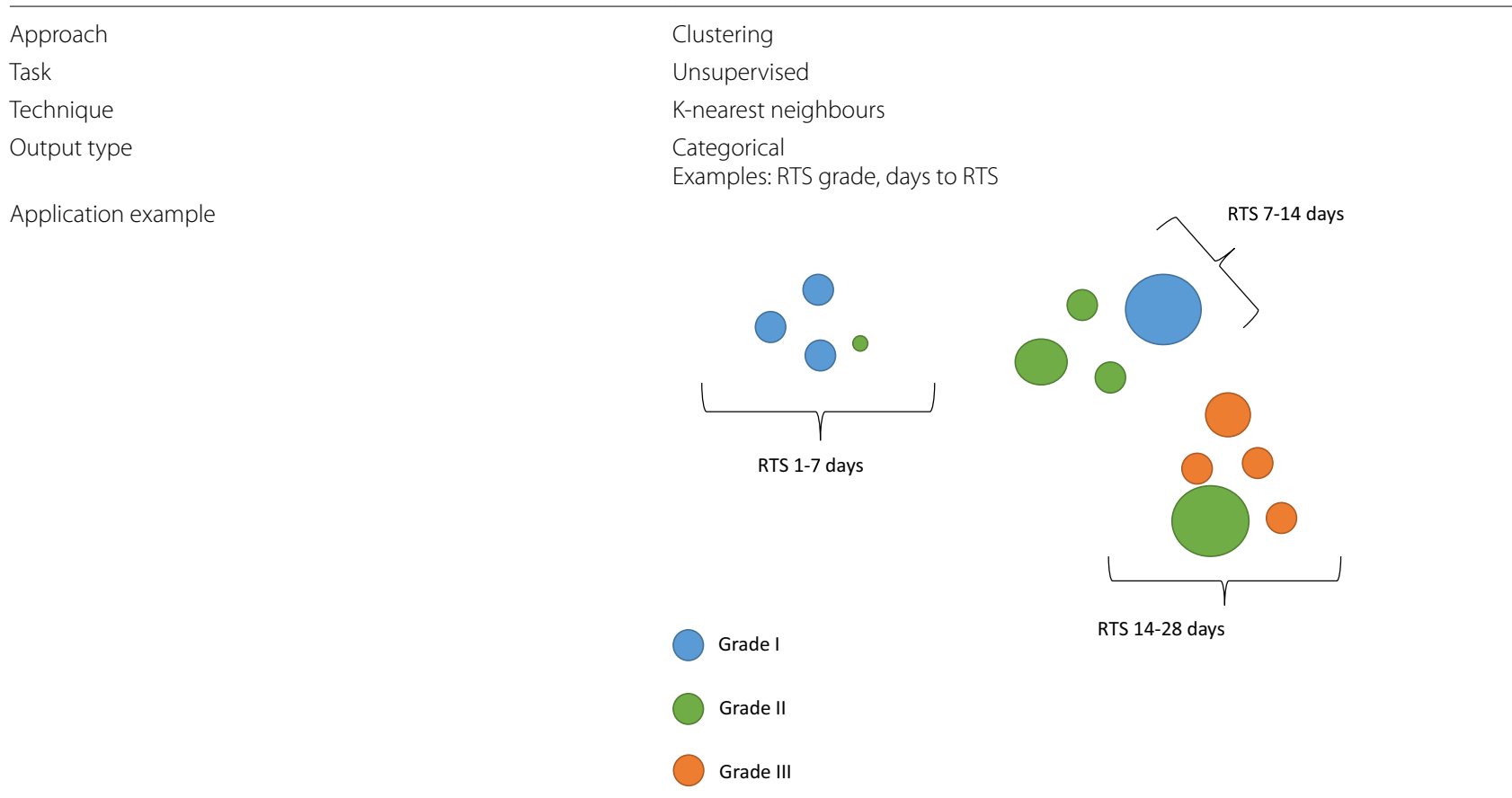

coach noticed that the athlete had a high level of mental readiness, as reflected by relevant measures (e.g., InjuryPsychological Readiness to Return to Sport scale [53]). The coach would like to know how this new information, combined with the previous knowledge, may change the practitioner's judgement. A relalationship modelling approach described below is used.

Relationship modelling involves estimating relationships between a dependent variable and one or more independent variables. Regression analysis, commonly used in the analysis, is also a type of relationship modelling technique and could be used with the complex systems approach. For example, it could be used for modelling the relationship between outcomes, such as match results [54] and injury incidence [45].

Table 5 shows a hypothetical example of how the confidence to RTS (y-axis) may be associated with the volume of high-speed running done ( $x$-axis) and the mentalreadiness score (size of the bubble). The level of mental readiness is denoted by the size of the bubble. A higher level of mental readiness is indicated with a larger size bubble and is in green colour. A lower level is indicated with a smaller size and is in red. The association could be multi-dimensional and could be constructed based on the number of inputs available, e.g., running speed, load accumulation, psychological readiness.

\section{Question 5: What is the Optimal Sequence of Rehabilitation in a Case of Hamstring Injury Rehabilitation?}

Scenario After reviewing the dataset, the coach and the clinician would like to explore how to further leverage the available data and identify adaptive personalized treatment plans in the future. Reinforcement learning may help to optimize the sequence of decisions that favour a long-term outcome. Reinforcement learning is described below.

Unlike supervised or unsupervised learning, reinforcement learning trains itself through trial and error to explore behaviours in the system that could maximize the reward [55]. This feature makes it suitable for solving sequential decision problems. In this clinical vignette, reinforcement learning could help to identify a personalized rehabilitation pathway for maximizing the reward (i.e., managing the injury or reaching the rehabilitation goal).

In the context of a hamstring injury (see Table 6), a practitioner has to decide when to initiate and adjust rehabilitation training, such as jogging, eccentric hamstring exercise, and high-speed running. Each decision affects the athlete's rehabilitation outcome at the end of the program and the total days of absence. The rewards require practitioners' input, such as comparing the intensity and volume of high-speed running to the pre-injury. The reliability of the treatment-quality estimate depends 
Table 5 The relationship modelling approach to identify the effect of mental readiness

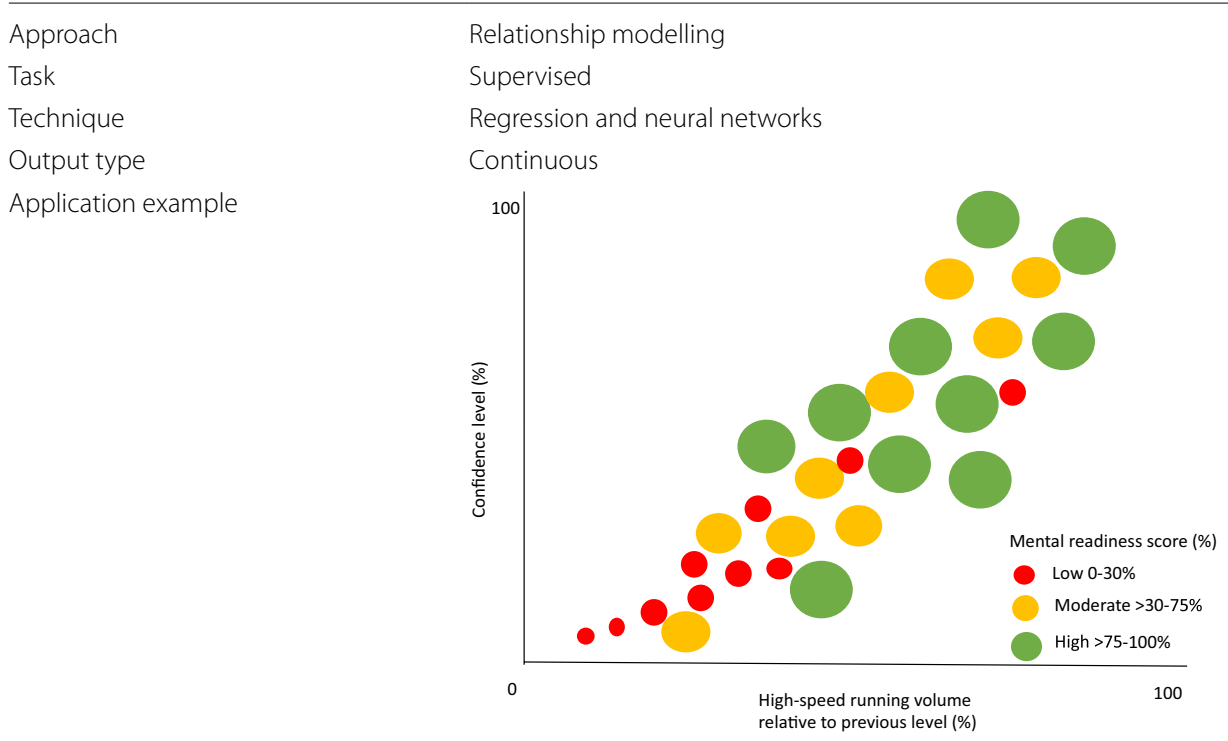

Table 6 Use of reinforcement learning to optimise the sequence of rehabilitation

\begin{tabular}{ll}
\hline Approach & Reinforcement learning \\
Task & Not applicable \\
Technique & Markov decision process \\
Output type \\
Application example
\end{tabular}

heavily on the amount of data that were used to train the algorithm used in the reinforced learning, and the extent to which the proposed and observed treatment policies agree.

\section{Bayesian Network}

Besides the machine learning approach, Bayesian methods are becoming increasingly popular in the study of sports [56] and may contribute to RTS. Various forms of $\mathrm{BN}$ have been applied across different sectors, including medical [57-61], ecology [62-64] and transportation [65].

BN uses Bayesian inference for probability computations and can be visually presented using directed acyclic graphs. Arrows on the BN, known as directed arcs, indicate the direction of the influence [66]. These show how various discrete or continuous factors in RTS influence one another and the outcome in a graphical presentation [66]. BN allows calculation of the conditional probabilities of the outcome of a decision when the value of some of the factors has been observed. As new evidence is revealed, changes are brought to the conditional probability of the decision outcome [67].

\section{Question 6: How Would the Sex of the Athlete Affect the Perceived ACL Injury Risk?}

Scenario The athlete has now recovered from the hamstring injury but is worried about the potential ACL injury risk. The coach wants to know how the sex of the athlete (prior) [as female] would affect how one perceives the ACL injury risk (outcome) [higher risk of ACL injury] 


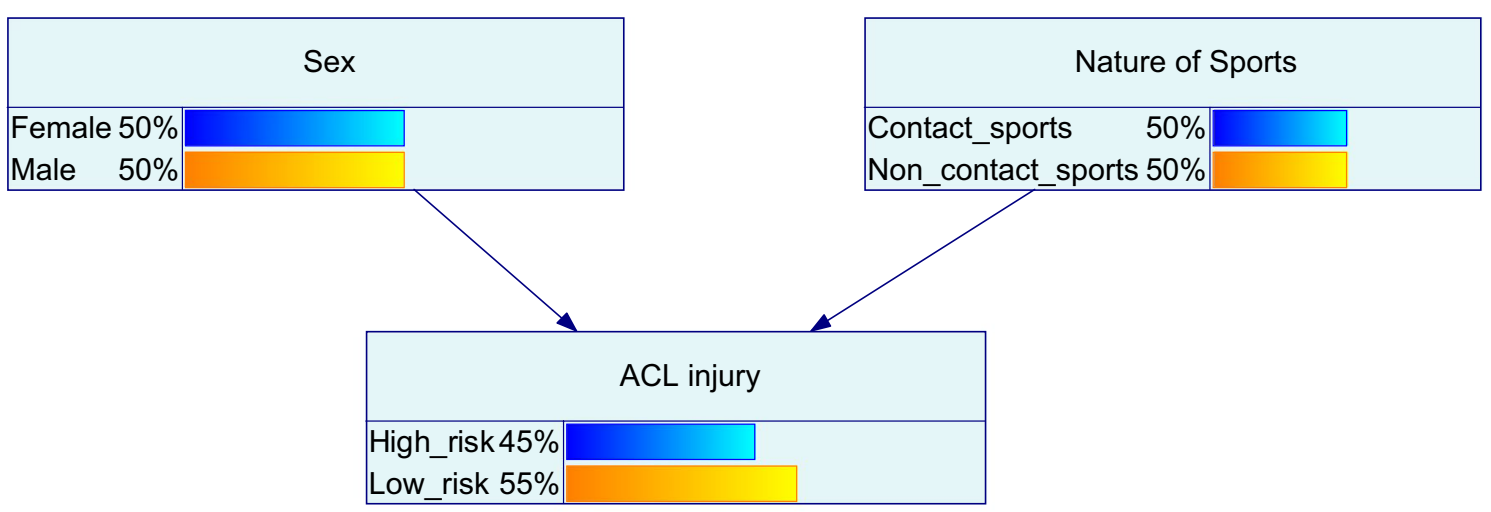

a The Bayesian network with no prior.

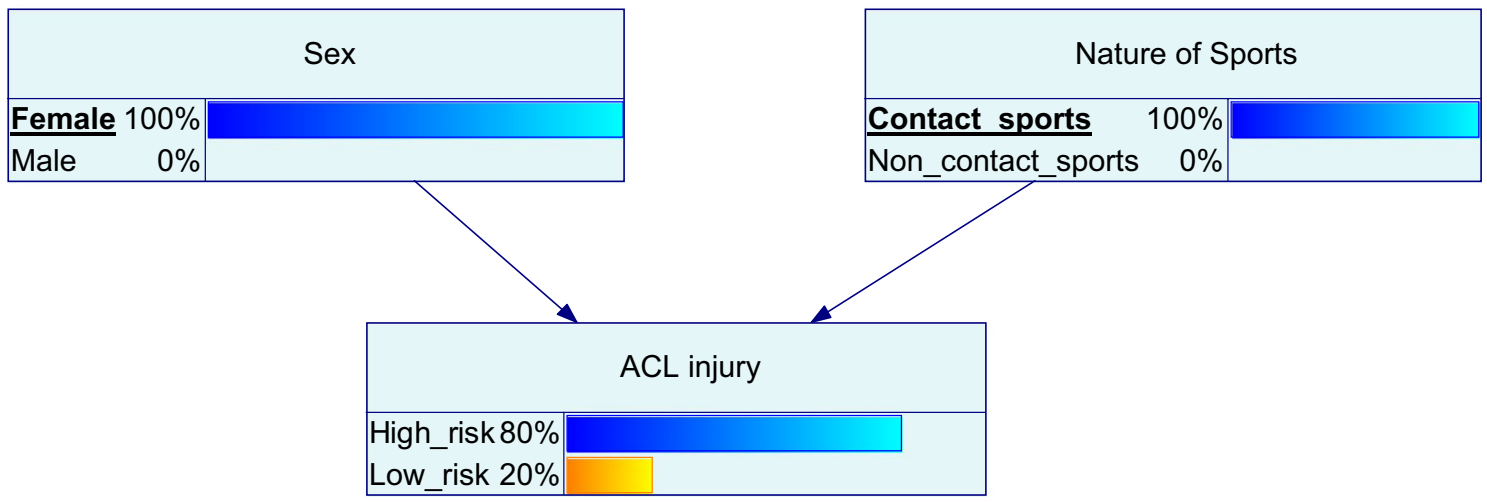

b The Bayesian network after it has been updated with prior.

Fig. 2 Illustration of a Bayesian network before (a) and after it has been updated with a prior (sex or/and nature of sport) (b). The outcome of the prediction (ACL injury risk) has changed as a result

(Fig. 2) [68], and how it may inform the potential consequence of a RTS decision.

Only one prior is used here to explain the application for easier understanding. However, a BN can account for multiple variables to increase the accuracy of the model and to acknowledge the complex systems approach, as seen from a hypothetical example here in Fig. 3.

A BN could be operated in both directions, performing both predictive and diagnostic inference. As an example, a BN may provide the following information to support RTS decisions: (1) given the observation of the athlete's rehabilitation markers, what is the likelihood for the athlete to perform at pre-injury level upon RTS? (2) to increase the likelihood to achieve certain outcomes of RTS, what is the combination of test results and/or observations required?

Logically, BN seems to fit into the requirement of RTS decisions, as often multiple unknown factors are involved in the process (e.g., how wellness may be associated with the injury risk). Although these unknown parameters are uncertain, they could be described by a probability distribution table, with information supplied by a domain expert or relevant literature.

Establishing a BN requires data and could be complemented by expert knowledge [66]. Expert knowledge allows the model to specify the decision options available and the utilities that the user is after. For example, decision-makers may decide if the utility (degree of satisfaction) of the RTS outcome is based on either maximising the team performance, minimising the risk of subsequent injury, or equilibrium between the two. However, this also implies that the quality of the model output would rely on the quality of the existing evidence and expert's knowledge, which may be flawed or biased.

\section{Future Research}

A shift towards a complex systems approach may help to view RTS more realistically. Future research should be mindful of the following issues:

(1) The complex systems approach and the machine learning techniques cannot necessarily elucidate the 


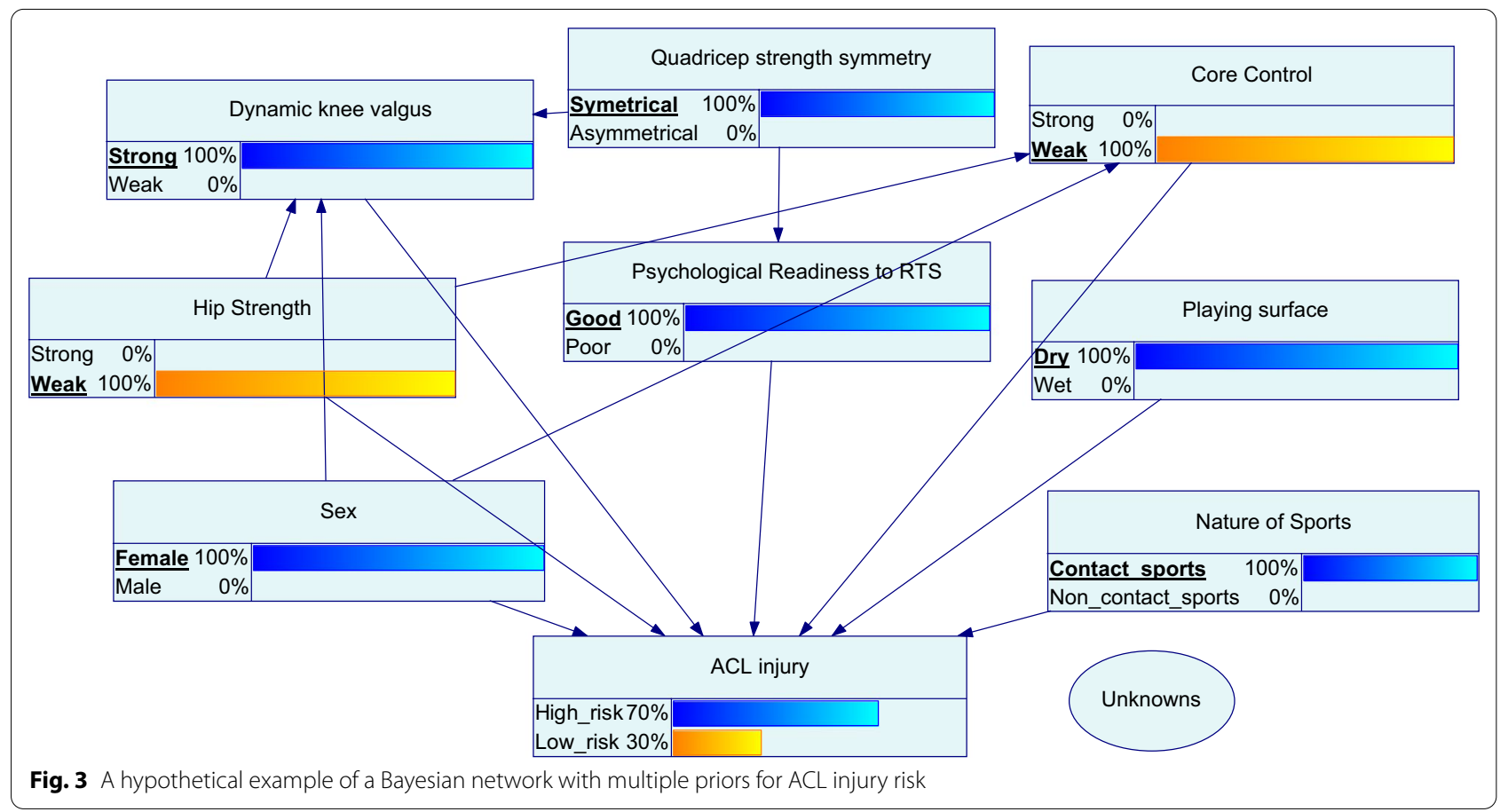

causal mechanism. Based on Table 1, the characteristics of complex systems do not permit cause and effect relationships to be determined. However, that does not imply they are inappropriate for understanding a problem nor they are of low practical utility.

(2) The accuracy of the computation relies heavily on the quality of the dataset and previous knowledge. For example, what is the association between different variables (e.g., age, playing style, previous injury history, culture, and lifestyle)? What is the potential effect of external factors (e.g., stress, financial pressure, lack of social support) on RTS progress and decision making? Currently, there is insufficient evidence on these aspects. High quality randomized controlled trials and longitudinal research that acknowledges the complex systems approach are required to observe regularities that are antecedent to the success of a rehabilitation program.

(3) The RTS systems that researchers could construct would consist of what is available and known, rather than what is important. Some factors may be difficult to measure due to the availability of time, resources and their non-deterministic or qualitative nature [69]. For example, motivation for RTS during rehabilitation is important but often not measured due to difficulty obtaining accurate feedback. However, this is inevitable, as unknowns and unpredictability are characteristics of complex systems. Nevertheless, if possible, real data should be applied to prove the concept and provide useful output for practitioners, as the ultimate goal of embracing complex systems approaches in RTS is to produce findings closer to the real world.

\section{Conclusion}

The complex systems approach has been applied to understand different aspects of sports science and medicine. This review has highlighted the characteristics and terminologies of complex systems, as exhibited by a case of ACL rehabilitation. When assessing the test result for clinical and functional tests, practitioners should also be aware of the dynamic systems evolving around the injury rehabilitation (refer to the examples in Table 1) and endeavour to understand the full picture. Future research may make use of computational modelling and machine learning techniques to identify the regularities of the pattern that emerges as a whole. A paradigm shift that results in the application of complex systems approach to understanding the RTS process and decision making should be encouraged.

\section{Abbreviations}

ACL: Anterior cruciate ligament; Al: Artificial intelligence; BDN: Bayesian decision network; BN: Bayesian network; RTS: Return-to-sport.

\section{Acknowledgements}

KY is supported by the Australian Government Research Training Program Scholarship. Our Bayesian network model was built using GeNIE Modeler (BayesFusion) from https://www.bayesfusion.com/. 


\section{Authors' contributions}

Conceptualization: KY and SR. Writing- original draft preparation: KY. Writingreview and editing: SR, CA, FS and KY. All authors read and approved the final manuscript.

\section{Authors' information}

$\mathrm{KY}$ is a physiotherapist and Ph.D. student within the Institute for Health and Sport at Victoria University in Melbourne, Australia. CLA is a senior researcher in the Department of Family Practice at the University of British Columbia in Vancouver, Canada. FS is an Associate Professor in Sports Physiology within the Institute for Health and Sport at Victoria University. SR is a Professor of Sports Analytics within the Institute for Health and Sport at Victoria University.

\section{Funding}

Open Access funding enabled and organized by CAUL and its Member Institutions. The authors declare that no funding was received for this review.

\section{Availability of data and materials}

Not applicable.

\section{Declarations}

Ethics approval and consent to participate

Not applicable- review article.

\section{Consent for publication}

Not applicable.

\section{Competing interests}

Kate Yung, Clare Ardern, Fabio Serpiello and Sam Robertson declare that they have no conflict of interest relevant to the content of this review.

\section{Author details}

${ }^{1}$ Institute for Health and Sport, Victoria University, Melbourne, Australia. ${ }^{2}$ Musculoskeletal and Sports Injury Epidemiology Centre, Department of Health Promotion Science, Sophiahemmet University, Stockholm, Sweden. ${ }^{3}$ Sport and Exercise Medicine Research Centre, La Trobe University, Melbourne, Australia. ${ }^{4}$ Department of Family Practice, University of British Columbia, Vancouver, Canada.

Received: 8 June 2021 Accepted: 29 December 2021

Published online: 22 February 2022

\section{References}

1. Hägglund M, Waldén M, Magnusson H, Kristenson K, Bengtsson H, Ekstrand J. Injuries affect team performance negatively in professional football: an 11-year follow-up of the UEFA Champions League injury study. Br J Sports Med. 2013;47(12):738-42.

2. Drew MK, Raysmith BP, Charlton PC. Injuries impair the chance of successful performance by sportspeople: a systematic review. Br J Sports Med. 2017;51(16):1209-14.

3. Williams S, Trewartha G, Kemp SPT, Brooks JHM, Fuller CW, Taylor AE, et al. Time loss injuries compromise team success in Elite Rugby Union: a 7-year prospective study. Br J Sports Med. 2016;50(11):651-6.

4. Hickey J, Shield AJ, Williams MD, Opar DA. The financial cost of hamstring strain injuries in the Australian Football League. Br J Sports Med. 2014;48(8):729-30.

5. Mather RC 3rd, Koenig L, Kocher MS, Dall TM, Gallo P, Scott DJ, et al. Societal and economic impact of anterior cruciate ligament tears. J Bone Joint Surg Am. 2013;95(19):1751-9.

6. Grindem H, Snyder-Mackler L, Moksnes H, Engebretsen L, Risberg MA. Simple decision rules can reduce reinjury risk by $84 \%$ after $\mathrm{ACL}$ reconstruction: the Delaware-Oslo ACL cohort study. Br J Sports Med. 2016;50(13):804-8.

7. Stares J, Dawson B, Peeling P, Drew M, Heasman J, Rogalski B, et al. How much is enough in rehabilitation? High running workloads following lower limb muscle injury delay return to play but protect against subsequent injury. J Sci Med Sport. 2018;21(10):1019-24.
8. Kyritsis P, Bahr R, Landreau P, Miladi R, Witvrouw E. Likelihood of ACL graft rupture: not meeting six clinical discharge criteria before return to sport is associated with a four times greater risk of rupture. Br J Sports Med. 2016;50(15):946-51.

9. Bittencourt NFN, Meeuwisse WH, Mendonça LD, Nettel-Aguirre A, Ocarino JM, Fonseca ST. Complex systems approach for sports injuries: moving from risk factor identification to injury pattern recognition - narrative review and new concept. Br J Sports Med. 2016;50(21):1309-14.

10. Bertalanffy LV. General system theory: foundations, development, applications. New York: George Braziller Inc; 1969.

11. Philippe $P$, Mansi O. Nonlinearity in the epidemiology of complex health and disease processes. Theor Med Bioeth. 1998;19(6):591-607.

12. Von Bertalanffy $L$. The theory of open systems in physics and biology. Science. 1950;111(2872):23-9.

13. Philippe P, Garcia MR, West BJ. Evidence of "'essential uncertainty"' in emergency-ward length of stay. Fractals. 2004;12(02):197-209.

14. Rickles D, Hawe P, Shiell A. A simple guide to chaos and complexity. J Epidemiol Community Health. 2007;61(11):933-7.

15. Hulme A, Salmon PM, Nielsen RO, Read GJM, Finch CF. From control to causation: validating a 'complex systems model' of running-related injury development and prevention. Appl Ergon. 2017;65:345-54.

16. Mclean S, Hulme A, Mooney M, Read GJM, Bedford A, Salmon PM. A sys tems approach to performance analysis in women's netball: using work domain analysis to model elite netball performance. Front Psychol. 2019;10:201.

17. Salmon PM, McLean S. Complexity in the beautiful game: implications for football research and practice. Sci Med Football. 2019;4:1-6.

18. Duarte R, Araújo D, Folgado H, Esteves P, Marques P, Davids K. Capturing complex, non-linear team behaviours during competitive football performance. J Syst Sci Complex. 2013;26(1):62-72.

19. Dalton-Barron N, Whitehead S, Roe G, Cummins C, Beggs C, Jones B. Time to embrace the complexity when analysing GPS data? A systematic review of contextual factors on match running in rugby league. J Sports Sci. 2020;38:1-20.

20. Lynch AD, Logerstedt DS, Grindem H, Eitzen I, Hicks GE, Axe MJ, et al. Consensus criteria for defining 'successful outcome' after ACL injury and reconstruction: a Delaware-Oslo ACL cohort investigation. Br J Sports Med. 2015;49(5):335-42.

21. Barber-Westin SD, Noyes FR. Factors used to determine return to unrestricted sports activities after anterior cruciate ligament reconstruction. Arthrosc J Arthrosc Relat Surg Off Publ Arthrosc Assoc N Am Int Arthrosc Assoc. 2011;27(12):1697-705.

22. Logerstedt D, Di Stasi S, Grindem H, Lynch A, Eitzen I, Engebretsen $L$, et al. Self-reported knee function can identify athletes who fail return-to-activity criteria up to 1 year after anterior cruciate ligament reconstruction: a delaware-oslo ACL cohort study. J Orthop Sports Phys Ther. 2014;44(12):914-23.

23. Hartigan EH, Axe MJ, Snyder-Mackler L. Time line for noncopers to pass return-to-sports criteria after anterior cruciate ligament reconstruction. J Orthop Sports Phys Ther. 2010;40(3):141-54.

24. Creighton DW, Shrier I, Shultz R, Meeuwisse WH, Matheson GO. Return-to-play in sport: a decision-based model. Clin J Sport Med. 2010;20(5):379-85.

25. Matheson GOMDP, Shultz RP, Bido J, Mitten MJJD, Meeuwisse WHMDP, Shrier IMDP. Return-to-play decisions: are they the team physician's responsibility? [miscellaneous article]. Clin J Sport Med. 2011;21(1):25-30.

26. Shrier I. Strategic assessment of risk and risk tolerance (StARRT) framework for return-to-play decision-making. Br J Sports Med. 2015;49(20):1311-5.

27. Joanna B, Alex P, Pete B-J, Martha B, Dione H. The visual representation of complexity: definitions, examples and learning points. RSD7, Relating Systems Thinking and Design. 2018;7.

28. Ekstrand JK, Krutsch W, Spreco A, van Zoest W, Roberts C, Meyer T, Bengtsson $\mathrm{H}$. Time before return to play for the most common injuries in professional football: a 16-year follow-up of the UEFA Elite Club Injury Study. Br J Sports Med. 2019;54(7):421-6.

29. Walden M, Hagglund M, Magnusson H, Ekstrand J. ACL injuries in men's professional football: a 15-year prospective study on time trends and 
return-to-play rates reveals only $65 \%$ of players still play at the top level 3 years after ACL rupture. Br J Sports Med. 2016;50(12):744-50.

30. Janssen KW, Orchard JW, Driscoll TR, van Mechelen W. High incidence and costs for anterior cruciate ligament reconstructions performed in Australia from 2003-2004 to 2007-2008: time for an anterior cruciate ligament register by Scandinavian model? Scand J Med Sci Sports. 2012;22(4):495-501.

31. van Melick N, van Cingel REH, Brooijmans F, Neeter C, van Tienen T, Hullegie W, et al. Evidence-based clinical practice update: practice guidelines for anterior cruciate ligament rehabilitation based on a systematic review and multidisciplinary consensus. Br J Sports Med. 2016;50(24):1506-15.

32. Anderson MJ, Browning WM 3rd, Urband CE, Kluczynski MA, Bisson LJ. A systematic summary of systematic reviews on the topic of the anterior cruciate ligament. Orthop J Sports Med. 2016;4(3):2325967116634074.

33. Paterno MV, Rauh MJ, Schmitt LC, Ford KR, Hewett TE. Incidence of second $\mathrm{ACL}$ injuries 2 years after primary $\mathrm{ACL}$ reconstruction and return to sport. Am J Sports Med. 2014;42(7):1567-73.

34. Della Villa F, Hägglund M, Della Villa S, Ekstrand J, Waldén M. High rate of second $A C L$ injury following $A C L$ reconstruction in male professional footballers: an updated longitudinal analysis from 118 players in the UEFA Elite Club Injury Study. Br J Sports Med. 2021:bjsports-2020-103555.

35. Peterson KD, Evans LC. Decision support system for mitigating athletic injuries. Int J Comput Sci Sport. 2019;18(1):45.

36. Kawamoto K, Houlihan CA, Balas EA, Lobach DF. Improving clinical practice using clinical decision support systems: a systematic review of trials to identify features critical to success. BMJ. 2005;330(7494):765

37. Martinez-Franco Al, Sanchez-Mendiola M, Mazon-Ramirez JJ, Hernandez-Torres I, Rivero-Lopez C, Spicer T, et al. Diagnostic accuracy in Family Medicine residents using a clinical decision support system (DXplain): a randomized-controlled trial. Diagnosis. 2018;5(2):71-6.

38. Kunhimangalam R, Ovallath $S$, Joseph PK. A clinical decision support system with an integrated EMR for diagnosis of peripheral neuropathy. J Med Syst. 2014;38(4):38.

39. Tibshirani GJDWTHR. An introduction to statistical learning. New York: Springer; 2013.

40. Mohammed M, Khan M, Bashier E. Machine learning: algorithms and applications. Florida: CRC Press; 2017.

41. SoleimanianGharehchopogh F, Mohammadi P, Hakimi P. Application of decision tree algorithm for data mining in healthcare operations: a case study. Int J Comput Appl. 2012;2012(52):21.

42. Witten IH, Frank E, Hall MA. Chapter 9-Moving on: applications and beyond. In: Witten IH, Frank E, Hall MA, editors. Data mining: practical machine learning tools and techniques. 3rd ed. Boston: Morgan Kaufmann; 2011. p. 375-99.

43. Edouard P, Verhagen E, Navarro L. Machine learning analyses can be of interest to estimate the risk of injury in sports injury and rehabilitation. Ann Phys Rehabil Med. 2020.

44. Han J. Data mining concepts and techniques. 3rd ed. Waltham: Morgan Kaufmann Publishers; 2012.

45. Ruddy J, Maniar N, Cormack S, Timmins R, Opar D. Predictive modelling of non-contact lower limb injuries in elite Australian footballers. J Sci Med Sport. 2018;21:S18.

46. Claudino JG, Capanema DdO, de Souza TV, Serrão JC, Machado Pereira AC, Nassis GP. Current approaches to the use of artificial intelligence for injury risk assessment and performance prediction in team sports: a systematic review. Sports Med Open. 2019;5(1):28.

47. Rossi A, Pappalardo L, Cintia P, laia FM, Fernández J, Medina D. Effective injury forecasting in soccer with GPS training data and machine learning. PLoS ONE. 2019;13(7):e0201264.

48. Cust EE, Sweeting AJ, Ball K, Robertson S. Machine and deep learning for sport-specific movement recognition: a systematic review of model development and performance. J Sports Sci. 2019;37(5):568-600.

49. Fältström A, Kvist J, Bittencourt NFN, Mendonça LD, Hägglund M. Clinical risk profile for a second anterior cruciate ligament injury in female soccer players after anterior cruciate ligament reconstruction. Am J Sports Med. 0(0):0363546521999109.

50. Agrawal R, Srikant R. Fast algorithms for mining association rules in large databases. In: Proceedings of the 20th international conference on very large data bases. Morgan Kaufmann Publishers Inc.; 1994. p. 487-99.

51. Albano TR, Rodrigues CAS, Melo AKP, de Paula PO, Almeida GPL. Clinical decision algorithm associated with return to sport after anterior cruciate ligament reconstruction. J Athl Train. 2020;55(7):691-8.

52. Jain AK, Dubes RC. Algorithms for clustering data. Hoboken: PrenticeHall, Inc.; 1988.

53. Glazer DD. Development and preliminary validation of the InjuryPsychological Readiness to Return to Sport (I-PRRS) scale. J Athl Train. 2009;44(2):185-9.

54. Robertson S, Back N, Bartlett JD. Explaining match outcome in elite Australian Rules football using team performance indicators. J Sports Sci. 2016;34(7):637-44.

55. Richard SS, Andrew GB. Reinforcement learning: an introduction. Adaptive computation and machine learning series. Cambridge: MIT Press; 1998. p. 3-24.

56. Santos-Fernández E, Wu P, Mengersen K. Bayesian statistics meets sports: a comprehensive review. J Quant Anal Sports. 2019;15(4):289-312

57. Yet B, Perkins ZB, Tai NRM, Marsh DWR. Clinical evidence framework for Bayesian networks. Knowl Inf Syst. 2017;50(1):117-43.

58. Yet B, Bastani K, Raharjo H, Lifvergren S, Marsh W, Bergman B. Decision support system for Warfarin therapy management using Bayesian networks. Decis Support Syst. 2013;55(2):488-98.

59. Seixas FL, Zadrozny B, Laks J, Conci A, Muchaluat Saade DC. A Bayesian network decision model for supporting the diagnosis of dementia, Alzheimer's disease and mild cognitive impairment. Comput Biol Med. 2014;51:140-58.

60. McLachlan S, Dube K, Hitman GA, Fenton NE, Kyrimi E. Bayesian networks in healthcare: distribution by medical condition. Artif Intell Med. 2020:107:101912.

61. Fenton N, McLachlan S, Lucas P, Dube K, Hitman G, Osman M, et al. A privacy-preserving Bayesian network model for personalised COVID1 9 risk assessment and contact tracing. medRxiv. 2020:2020.07.15.20154286.

62. Wu PP-Y, Mengersen K, McMahon K, Kendrick GA, Chartrand K, York $\mathrm{PH}$, et al. Timing anthropogenic stressors to mitigate their impact on marine ecosystem resilience. Nat Commun. 2017;8(1):1263.

63. Johnson S, Mengersen K, de Waal A, Marnewick K, Cilliers D, Houser AM, et al. Modelling cheetah relocation success in southern Africa using an Iterative Bayesian Network Development Cycle. Ecol Model. 2010:221(4):641-51

64. Wu PP-Y, McMahon K, Rasheed MA, Kendrick GA, York PH, Chartrand $\mathrm{K}$, et al. Managing seagrass resilience under cumulative dredging affecting light: predicting risk using dynamic Bayesian networks. J Appl Ecol. 2018;55(3):1339-50.

65. Wu PPY, Pitchforth J, Mengersen K. A hybrid queue-based Bayesian network framework for passenger facilitation modelling. Transp Res Part C Emerg Technol. 2014;46:247-60.

66. Constantinou A, Fenton N. Things to know about Bayesian networks. Significance. 2018;15:19-23.

67. Eugene C. Bayesian networks without tears. Al Mag. 1991;12(4):50-63.

68. Montalvo AM, Schneider DK, Yut L, Webster KE, Beynnon B, Kocher MS, et al. "What's my risk of sustaining an $A C L$ injury while playing sports?" A systematic review with meta-analysis. Br J Sports Med. 2019;53(16):1003-12.

69. Bourne M, Neely A, Mills J, Platts K. Implementing Performance Measurement Systems: A Literature Review. Int J Business Performance Management. 2003:5:1-24.

70. Davids K. Complex systems in sport. 2014

71. Holland JH. Complexity: a very short introduction. Oxford: Oxford University Press; 2014

72. Grooms DR, Page SJ, Nichols-Larsen DS, Chaudhari AMW, White SE, Onate JA. Neuroplasticity associated with anterior cruciate ligament reconstruction. J Orthop Sports Phys Ther. 2016;47(3):180-9.

73. Davids K, Kingsbury D, George K, O'Connell M, Stock D. Interacting constraints and the emergence of postural behavior in ACL-Deficient Subjects. J Motor Behav. 1999;31(4):358-66. 
74. Grindem $\mathrm{H}$, Risberg MA, Eitzen I. Two factors that may underpin outstanding outcomes after ACL rehabilitation. Br J Sports Med. 2015;49(22):1425

75. Donnelly CJ, Elliott BC, Doyle TLA, Finch CF, Dempsey AR, Lloyd DG. Changes in knee joint biomechanics following balance and technique training and a season of Australian football. Br J Sports Med. 2012;46(13):917-22.

76. Arhos EK, Capin JJ, Buchanan TS, Snyder-Mackler L. Quadriceps strength symmetry does not modify gait mechanics after anterior cruciate ligament reconstruction, rehabilitation, and return-to-sport training. Am J Sports Med. 2021;49(2):417-25.

77. Roberts CS, Rash GS, Honaker JT, Wachowiak MP, Shaw JC. A deficient anterior cruciate ligament does not lead to quadriceps avoidance gait. Gait Posture. 1999;10(3):189-99.

78. Pandy MG, Shelburne KB. Dependence of cruciate-ligament loading on muscle forces and external load. J Biomech. 1997;30(10):1015-24.

79. Li G, Rudy TW, Sakane M, Kanamori A, Ma CB, Woo SLY. The importance of quadriceps and hamstring muscle loading on knee kinematics and in-situ forces in the ACL. J Biomech. 1999;32(4):395-400.

80. Cavanaugh JT, Powers M. ACL rehabilitation progression: where are we now? Curr Rev Musculoskelet Med. 2017;10(3):289-96.

81. Bousquet BA, O'Brien L, Singleton S, Beggs M. Post-operative criterion based rehabilitation of acl repairs: a clinical commentary. Int J Sports Phys Ther. 2018;13(2):293-305.

82. Taberner M, van Dyk N, Allen T, et al. Physical preparation and return to performance of an elite female football player following $A C L$ reconstruction: a journey to the FIFA Women's World Cup. BMJ Open Sport Exerc Med. 2020;6(1):1-24.

83. Gokeler A, Bisschop M, Benjaminse A, Myer GD, Eppinga P, Otten E. Quadriceps function following ACL reconstruction and rehabilitation: implications for optimisation of current practices. Knee Surg Sports Traumatol Arthrosc. 2014;22(5):1163-74.

84. Kraemer WJ, Ratamess NA. Hormonal responses and adaptations to resistance exercise and training. Sports Med. 2005;35(4):339-61.

85. Kibler WB, Chandler TJ, Stracener ES. Musculoskeletal adaptations and injuries due to overtraining. Exerc Sport Sci Rev. 1992;20:99-126.

86. Langford JL, Webster KE, Feller JA. A prospective longitudinal study to assess psychological changes following anterior cruciate ligament reconstruction surgery. Br J Sports Med. 2009;43(5):377-8.

87. Faulkner JA, Davis CS, Mendias CL, Brooks SV. The aging of elite male athletes: age-related changes in performance and skeletal muscle structure and function. Clin J Sport Med. 2008:18(6):501-7.

88. Gellish RL, Goslin BR, Olson RE, McDonald A, Russi GD, Moudgil VK. Longitudinal modeling of the relationship between age and maximal heart rate. Med Sci Sports Exerc. 2007;39(5):822-9.

89. Wilson TM, Tanaka H. Meta-analysis of the age-associated decline in maximal aerobic capacity in men: relation to training status. Am J Physiol-Heart Circ Physiol. 2000;278(3):H829-34.

90. Dowling AV, Corazza S, Chaudhari AM, Andriacchi TP. Shoe-surface friction influences movement strategies during a sidestep cutting task: implications for anterior cruciate ligament injury risk. Am J Sports Med. 2010;38(3):478-85.

91. Thomson A, Whiteley R, Bleakley C. Higher shoe-surface interaction is associated with doubling of lower extremity injury risk in football codes: a systematic review and meta-analysis. $\mathrm{Br} J$ Sports Med. 2015;49(19):1245-52.

92. Karageorghis $\mathrm{Cl}$, Hutchinson JC, Jones L, Farmer HL, Ayhan MS, Wilson RC, et al. Psychological, psychophysical, and ergogenic effects of music in swimming. Psychol Sport Exerc. 2013;14(4):560-8.

93. Gabana NT, Van Raalte JL, Hutchinson JC, Brewer BW, Petitpas AJ. The effects of music and a coxswain on attentional focus, perceived exertion, motivation, and performance during a 1000 m ergometer rowing sprint. J Appl Sport Psychol. 2015;27(3):288-300.

94. Kawamura S, Ying L, Kim HJ, Dynybil C, Rodeo SA. Macrophages accumulate in the early phase of tendon-bone healing. J Orthopaed Res Off Publ Orthop Res Soc. 2005:23(6):1425-32.

95. Arnoczky SP, Tarvin GB, Marshall JL. Anterior cruciate ligament replacement using patellar tendon. An evaluation of graft revascularization in the dog. J Bone Joint Surg Am. 1982;64(2):217-24.

96. Ithurburn MP, Paterno MV, Ford KR, Hewett TE, Schmitt LC. Young athletes with quadriceps femoris strength asymmetry at return to sport after anterior cruciate ligament reconstruction demonstrate asymmetric single-leg drop-landing mechanics. Am J Sports Med. 2015;43(11):2727-37.

97. Lewek M, Rudolph K, Axe M, Snyder-Mackler L. The effect of insufficient quadriceps strength on gait after anterior cruciate ligament reconstruction. Clin Biomech. 2002;17(1):56-63.

98. Kuenze CM, Hertel J, Weltman A, Diduch D, Saliba SA, Hart JM. Persistent neuromuscular and corticomotor quadriceps asymmetry after anterior cruciate ligament reconstruction. J Athl Train. 2015;50(3):303-12.

99. Lepley AS, Gribble PA, Thomas AC, Tevald MA, Sohn DH, Pietrosimone BG. Quadriceps neural alterations in anterior cruciate ligament reconstructed patients: a 6-month longitudinal investigation. Scand J Med Sci Sports. 2015:25(6):828-39.

100. Luc-Harkey BA, Harkey MS, Pamukoff DN, Kim RH, Royal TK, Blackburn $\mathrm{JT}$, et al. Greater intracortical inhibition associates with lower quadriceps voluntary activation in individuals with ACL reconstruction. Exp Brain Res. 2017;235(4):1129-37.

101. Zarzycki R, Morton SM, Charalambous CC, Marmon A, Snyder-Mackler L. Corticospinal and intracortical excitability differ between athletes early after ACLR and matched controls. J Orthop Res Off Publ Orthop Res Soc. 2018;36(11):2941-8.

102. Steding-Ehrenborg K, Hedén $B$, Herbertsson P, Arheden H. A longitudinal study on cardiac effects of deconditioning and physical reconditioning using the anterior cruciate ligament injury as a model. Clin Physiol Funct Imaging. 2013;33(6):423-30.

103. Almeida AMd, Santos Silva PR, Pedrinelli A, Hernandez AJ. Aerobic fitness in professional soccer players after anterior cruciate ligament reconstruction. PLoS ONE. 2018;13(3):e0194432-e.

104. Magyar TM, Duda JL. Confidence restoration following athletic. Injury. 2000;14(4):372

105. Carson F, Polman RCJ. ACL injury rehabilitation: a psychological case study of a professional rugby union player. J Clin Sport Psychol. 2008:2(1):71-90.

106. Podlog $L$, Eklund RC. A longitudinal investigation of competitive athletes' return to sport following serious injury. J Appl Sport Psychol. 2006;18(1):44-68.

\section{Publisher's Note}

Springer Nature remains neutral with regard to jurisdictional claims in published maps and institutional affiliations.

\section{Submit your manuscript to a SpringerOpen ${ }^{\circ}$ journal and benefit from:}

- Convenient online submission

- Rigorous peer review

- Open access: articles freely available online

- High visibility within the field

Retaining the copyright to your article

Submit your next manuscript at springeropen.com 